ing them all over except the face with the entrails of slaughtered animals, or the stomachs were eut open and the patients covered with fresh tripe. The treatment was repeated daily, and this was the treatment given the patient, repeated daily for many days.

During his ehildhood and manhood he has been singularly free from contact with the lower animals that might brimgr him infection. At an carly age he was apprenticed to a machinist. He left Russia when he was 18 , and since that time has never been in any purt of the world in which echinococcus diseuse was endemic. $\mathrm{He}$ is a man of more than ordinary intelligence, cleanly and careful in his personal habits and able to give a clear and concise account of his life and mode of living. It is improbable that he contracted the infection through any carelessness or ignorance on his part.

This brings us to the consideration of the probable time and manner of infection in this case. For the past scventeen years - since leaving Russin-he has led a cleanly life in a part of the world where echinococeus disense is very rare if not entirely unknown. Consequently, I believe we may infer that the chance of his infection during the past seventeen years was very slight.

Concerning the first eighteen years of his life, conditions were somewhat different. He lived in a country where echinococeus disense occur's and we must admit the possibility of infection taking place at any time; yet he gives a history of his earlier years that would seem to make the likelihood of infection slight. His home had no domestic pets, he never played with ents, dogs, sheep or other domestic animals that might transmit the infection, while his trade, that of a machinist, had a tendency to keep him away from the most common sources of infection.

So we are brought again to consider the chances of infection at the age of 2 years when he was buried repeatedly in the entrails of slaughtered animals, and probably beyond a doubt some of them were of cattle or shcep suffering from hydatid discase. The exceedingly close contact with infection which would be brought about by this treatment would seem to malke infection not only possible, but probable. Infection probably occurred by ingestion of the ovum and direct migration of the ovum through the wall of the stomach into the pancreas, where it began to develop.

By the appearance of the cyst I would say it had probably been dead for a long time, perhaps a number of years. While the duration of this cyst is merely a matter of conjecture, the history and circumstances are such that one may say there could well be no stronger evidence to a duration of thirty-three years.

The cyst was in a position in which palpation was impossible and percussion would reveal nothing. As it did not interfere with the function of at least part of the pancreas, I belicve that it gave rise to no symptoms which might even lead us to suspect the trouble and would be found only on the operating-table or at necropsy.

I wish to thank Colonel W. C. Gorgas for permission to pullish this poper.

Hexamethylenamin Used to Preserve Caviar.--Our vice-con. sul at Moscow writes that the anthorities have been petitioned by the Astraklian Chamber of Commerce to sanction the use of hexamethylenamin us a preservative of caviar until a more satisfactory preparation is found. Of about $1,400,000$ pounds of caviar obtained each year by the Astrakhan fisheries, approximately 75 per cent. is exported, and the only preservative thus far found which will keep the caviur fresh is hexamethylentmin. This substance is added to the caviar in the proportion of $1: 1300$ and therefore, it is claimed, is not present in amounts suflicient to be injurious to health. Approximately 100 pounds of licxumethylenamin are used for this purpose annually.-(Consular Reports, Nov. 0, 1913.)

\section{A NEW OPERATIVE TREATMENT FOR SPASTIC PARALYSIS}

PRELIMINARY IREPOI'T

WIJIJIAM SHARPE, M.D.

Adlunet Prof'ssor of Surgery, New York Polyclinic Medical School AND

BIENJAMIN P. FARIELL, M.D.

Vistting Surgeon, New York Orthopedic Dispensary and Hospital NEw YorK

The purpose of this article is to offer a new operative treatment in selected cases of spastic paralysis. We have now a series of only twelve cases to report, but the results have been so gratifying and even startling, that we feel justified in making a report of the work that has been done up to the present time. We do not assert that the improvement in all of our cases will be a permanent one (suffleient time has not yet elapsed since the operations), and yet we do not see why the improvement should not continue to be more and more marked as the children grow older.

Spastic paralysis is a condition which frequently results from a lesion of the brain occurring before birth, during birth or shortly after birth. It is characterized by more or less complete paralysis of the part affected, and is associated with a stiffness or spasticity depending on the extent of the involvement of the pyramidal tract; this hypertonicity produces muscular contractures and deformities, usually flexor in type, with a corresponding overstretching of the opposing muscular groups, usually the extensors. In mild cases, however, the spasticity may be so slight as to cause little or no deformity, but merely an awkwardness of the part affected. Frequently athetoid movements of the arms and legs may be observed, and epileptiform attacks, commonly of the Jacksonian type, may occur.

In a large percentinge of cases as the child grows older, not only do the spasticity and its resulting.contractures increase, but also the mentality of the child becomes impaired, and this mental impairment continues until the child may be considered a defective, or still further an imbecile, and only too frequently an jliot.

The most common lesion of the brain producing spastic paralysis is that of intracranial hemorrhage of the new-born. It is usually due to a rupture and tear of either the longitudinal sinus or of its venous tributaries, and of vessels overlying the cortex of the brain, causing a hemorrhagic clot to form over the cerebral cortex. According to the extent and pressure of this hemorrlage over the cerebral cortex, we find elinically the signs of such interference of the pyramidal tract-a spastic diplegia, paraplegia, hemiplegia and the milder forms of spastic paralysis. These lesions form 70 per cent. of the cases of spastic paralysis, whereas agenesis and maldevelopment of the cerebral cortex and the cases of meningo-encephalitis complicating measles and scarlet fever constitute most of the remaining 30 per cent.

The operations which have been used in the past and are still being used to improve the conditions of spastic paralysis, namely, tenotomies, tendon lengthenings, sec"tions of the posterior nerve roots, alcohol injections of peripheral nerves, nerve resections and other operations, are, in our opinion, of only temporary benefit, and we have yet to see a case in which the spasticity has not returned, in some degree, within one year. In all of our cases treated by the operations just mentioned during the past two and one-lualf years, the spasticity began to reappear within one year after operation. 
Tenotomies, hcsides being insurgical, are unsatisfactory. 'T'endon lengthenings (Hibbs' operation) àlone are satisfactory in only very mild cases. Foerster's operation for sectioning of the posterior nerve roots of the spinal cord is advocated merely to lessen the irritability and the instability of the cortex of the brain by decreasing the number of afferent stimuli reaching the brain througl the posterior nerve roots of the spinal cord and also to affect the reflex mechanism of the spinal cord. Besides being a rather formidable and long operation for a child, the lessening of the spasticity is only temporary, few cases being reported improved longer than one year. Our experience with seven cases has been the same. 'The injection of alcohol into the peripheral nerves (the Allison and Schwal operation) produces immediate paralysis and a temporary relief from spasticity; in our experience of thirty-one cases, however, the spasticity has returned within one year. With nerve resections (Stuffell's operation), we have had no experience. These operations, however, do not in any way "get at" the primary cause of the spastic paralysis, namely, the lesion of the brain, but are merely peripheral operations to relieve the spasticity temporarily, in the hope that, before the reeurrence of the spasticity, sufficient power will have returned to the opposing nuscular groups to reestablish the muscle bnlance. Iittle, if anything, has been done to improve permancntly the condition of spastic paralysis, and we offer our observations in the hope that they may land to a more satisfactory solution of the treatment of these pitiful cases. Our attention was first centered on the importance of relieving the inereased intracranial pressure as a means of lessening the spastieity and improving the mentality of these children, by a decompression operation pefformed by one of us.

\section{REPOR'T OF CASES}

Case 1.-The patient, a child, nged 9, with a left spastic hemiplegia of the flexor type, was moribund at the time of operntion, laving been in stutus epileptieus for three days, with little or no nourishment. Artificial respiration and oxygen were being used. The intracranial pressure was very high as shown by an ophthalmoseopic examination and by the signs of medulary compression, and therefore a decompression wos performed in the hope that a lowering of the intracrunia! pressure would afford the child its only opportunity to recover. The usual incision was made. The dura was very tense, and when it was incised, cerebrospinal fluid spurted to a lieight of 4 inches. Signs of an old cortical lemorrhnge were found, and $2 \mathrm{~cm}$. above the upper bony margin of the decompression opening was a rather hard, fibrous tumor, the size of an English wahut. As the condition of the child was precarious, it was thought wiser to remove the tumor at a subsequent operation. The child made in excellent recovery; the spasticity, however, lessened to such a degree that lic ean walk now with only a slight limp), the heel touching the floor; the left arm and the left himd nre now being used for the first time in his life. The aftertreatment is being carried out now with the cooperation of the child-something impossible before operation. As the child has improved so much, the parents have not yet consented to the second operation for removal of the tumor.

CAse 2,-The putient, a child of 13 , with a history typical of intracrunial hemorrlage of the new-born, was a spastic hemiplexgic, and on ophthinlmoscopic examination, signs of intracrunial pressure were observed. Remembering the impovement of the preceding case following a mere decompression operation, we advised and obtained consent for the oyerntion merely to relieve the intracranial pressure in the lope that the spasticity would be lessened and the mentality improved. Similar improvement followed as in the preeding rase, although a lengthening of the Achilles tendon was deemed advisable and it was performed the following week.
Sinec then we have performed the decompression operation in twelve selected cases in all and practically the same improvement has resulted in each case. We have selected for operation only the extreme types of spastic cases.

\section{METIIOD OF PROCEDURE}

In those cases of spastic paralysis of the hemiplegic, paraplegic or diplegic type, with a definite history of dilfieult labor with or without the use of instruments, in which, on ophthalmoscopic examination, signs of intracranial pressure are shown in the dilated retinal veins and a blurring and haziness of the optic disks, especially of their nasal halves, a large right subtemporal decompression is performed to relieve the intracranial pressure. If the intracranial pressure is extremely high and remains high after operation, a left subtemporal decompression is performed the following month, the operative recovery requiring only a week to ten days.

The method of dealing with the various pathologic lesions found at operation will be discussed in detail in the more complete report to be published later. The usual findings are definite cystic formations resulting from a cortical hemorrilage occurring at birth. The decompression operation is performed merely to of fset the eflects of the pressure of this hemorrhage with eystic formation, and the resulting spasticity and mental impairment.

The after-treatment consists in the correction of deformities by tendon lengthenings or stretchings of the contracted muscles, the maintenance of corrected positions through the employment of especially adapted and properly fitting braces, and skilled mussage in conjunction with short applications of galvanism and faradism, particular attention being given to the weakened and overstretched muscle groups. A careful, systematic course in muscle training is carried on daily.

'I'he improvement in our eases selected for operation has been so marked-not only a lessening of the spasticity, but a definite amelioration of the mental condition of the patient-that we believe a cranial decompression is indicated in those cases of spastic paralysis showing intracranial pressure by the ophthnlmoscopic examination; of those cases of spastic paralysis which we have examined, about 60 per cent. have shown signs of intracranial pressure, and are, therefore, in our opinion, chics that can be very much inproved. This operation is not a formidable procedure for one trained in neurologic surgery; all of our patients have improved and we have had no deaths. 'llie anesthetic should be administered by an expert.

One of the most important advantrges of this operation is that the child improves mentally to such a degree that we obtain the cooperation of the patient in the carrying out of the after-treatment.

Naturally, we do not believe that all cases of spastic paralysis sliould have a cranial decompression; in some mild cases, tendon lengthenings alone are sufficient, and this is especially true in the absence of mental impairment. But those selected cases of spastic paralysis, particularly of the hemiplegie and of the paraplegic types, which show signs of increased intracranial pressure by an ophthalmoscopic examination, are the cases that can be very much improved by such a procedure. The cases of agenesis and maldevelopment of the cortex of course cannot and do not show signs of increased intracranial pressure, and are therefore easily excluded by an ophthalmoscopic examination.

A more complete report will be published later.

20 West liftieth street-104 East liortieth Street. 